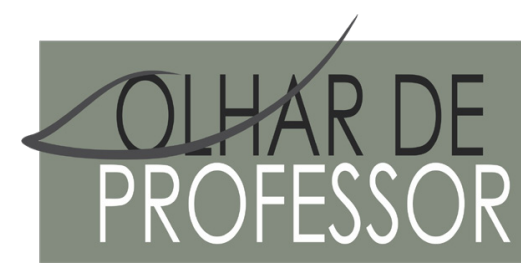

DOl: 10.5212/OLHARPROFR.v23.2020.15197.209209224492.0423

\title{
DESAFIOS E CONTRADIÇÕES DE PROFESSORES DA PARAÍBA ACERCA DA INCLUSÃO E DO ATENDIMENTO EDUCACIONAL ESPECIALIZADO
}

\author{
CHALLENGES AND CONTRADICTIONS OF TEACHERS FROM PARAÍBA ABOUT INCLUSION AND SPECIALIZED \\ EDUCATIONAL SERVICE
}

\section{DESAFÍOS Y CONTRADICCIONES DE LOS PROFESORES DE PARAÍBA ACERCA DE LA INCLUSIÓN EDUCATIVA Y EL SERVICIO EDUCATIVO ESPECIALIZADO}

\section{JULIANA MEDEIROS FERNANDES* MUNIQUE MASSARO ${ }^{* *}$}

\begin{abstract}
Resumo: O objetivo desta pesquisa é analisar a percepção de professores acerca da inclusão e do Atendimento Educacional Especializado nas escolas municipais do Estado da Paraíba. Assim, foi realizada uma entrevista semiestruturada com duas professoras do ensino regular e duas professoras do Atendimento Educacional Especializado. Após as entrevistas, elas foram transcritas e analisadas a partir de temas de análise. A partir deste estudo, percebe-se a necessidade de os profissionais trabalharem de forma mais colaborativa, a fim de favorecer a aprendizagem de alunos público-alvo da Educação Especial e promover a inclusão. Ademais, evidenciou-se que as professoras não têm formação específica e conhecimento de suas responsabilidades, além de se mostrarem resistentes à ideia de que a responsabilidade do sucesso ou fracasso dos alunos é de todos os profissionais da escola.
\end{abstract}

Palavras-chave: educação especial; profissionais da educação; funções docentes

\begin{abstract}
The objective of this research is to analyze the perception of teachers about inclusion and Specialized Educational Service in municipal schools in the State of Paraíba. Thus, a semi-structured interview was conducted with two teachers of regular education and two teachers of Specialized Educational Service. After the interviews, they were transcribed and analyzed based on analysis topics. Based on this study, the need for professionals to work collaboratively is perceived in order to favor the learning of targeted Special Education pupils as well as to promote inclusion. Furthermore, it became evident that the teachers do not have specific training and knowledge of their responsibilities, in addition to being resistant to the idea that the responsibility for the success or failure of the students belongs to all school professionals.
\end{abstract}

Keywords: special education; education professionals; teaching functions

Resumen: El objetivo de esta investigación es analizar la percepción que tienen los profesores sobre la inclusión educativa y el Servicio Educativo Especializado en los colegios municipales del Estado de Paraíba. Para ello, se realizó una entrevista semiestructurada con dos docentes de educación regular y dos docentes que pertenecen al Servicio Educativo Especializado. Después de la realización de las entrevistas, estas fueron transcritas y analizadas con base a los temas de análisis propuestos. A partir de este estudio, se percibe la necesidad de que los docentes deban trabajar de manera más colaborativa para favorecer el aprendizaje de los estudiantes del segmento de Educación Especial para promover su inclusión. También se hizo evidente que los docentes no poseen la necesaria

\footnotetext{
* Graduada em Pedagogia pela Universidade Federal da Paraíba.

*** Doutora do Programa de Pós-Graduação em Educação da Universidade Estadual Paulista “Júlio de Mesquita Filho” - campus de Marília. Docente Adjunta do Departamento de Habilitações Pedagógicas e do Programa de Pós-Graduação em Educação da Universidade Federal da Paraíba. Linha de pesquisa: Educação Especial no Brasil.
} 
capacitación específica ni el conocimiento de sus responsabilidades, además de mostrarse resistentes a la idea de que la responsabilidad del éxito o fracaso de los estudiantes, pertenece a todos los profesionales de la escuela.

Palabras-clave: educación especial; profesionales de la educación; funciones de los docentes

\section{INTRODUÇ̄̃O}

O acesso à educação é um direito de todo ser humano e um princípio fundamental da inclusão. Na perspectiva da educação inclusiva, a escola assume um papel decisivo e central para garantir as condições de acesso, participação e aprendizagem de todos os alunos em igualdades de condições, em todas as escolas regulares de ensino. Sendo assim, documentos como a Declaração de Salamanca defendem que a escola deve assegurar e garantir a educação de pessoas com deficiência e propiciar a mesma educação dada a todas as crianças, atendendo às suas especificidades (UNESCO, 1994). A Convenção Internacional sobre os Direitos das Pessoas com Deficiência, ratificada pelo Brasil via Decreto n ${ }^{0}$ 6.949/2009, em seu artigo $9^{\circ}$, dispôs que "os Estados devem assegurar às pessoas com deficiência o acesso, em igualdade de oportunidades, ao meio físico, ao transporte, à informação e comunicação” (ONU, 2006, p. 35).

Nesse contexto da educação inclusiva, a pessoa com deficiência passa a receber um novo olhar, no qual não são mais acentuadas as suas limitações, mas, sim, sua capacidade de aprendizagem, daí surge um novo conceito de deficiência com o objetivo de romper com o paradigma integracionista, que era focado no modelo clínico da deficiência. A Convenção Internacional sobre os Direitos das Pessoas determinou que:

Pessoas com deficiência são aquelas que têm impedimentos de longo prazo de natureza física, mental, intelectual ou sensorial, os quais, em interação com diversas barreiras, podem obstruir sua participação plena e efetiva na sociedade em igualdade de condições com as demais pessoas (ONU, 2006, p. 26).

Em 2008, estabeleceu-se a Política Nacional de Educação Especial na Perspectiva da Educação Inclusiva, que é um documento orientador para estados e municípios organizarem suas ações no sentido de transformarem seus sistemas educacionais em sistemas educacionais inclusivos (BRASIL, 2008). Além disso, em 2015, a Lei Brasileira de Inclusão da Pessoa com Deficiência, Lei no 13.146/2015, reforçou que a educação constitui direito da pessoa com deficiência, assegurado o sistema educacional inclusivo em todos os níveis e aprendizado ao longo de toda a vida (BRASIL, 2015, p. 6). Na busca de repensar o espaço escolar, os diversos movimentos e debates acerca da Educação Especial tornaram-se fundamentais para transformação do sistema educacional. Nessa direção, as leis acerca da inclusão exercem um papel crucial para eliminar as lacunas existentes no processo educativo, pois, por meio delas, torna-se possível permitir ao aluno o acesso aos bens da humanidade.

A Política Nacional de Educação Especial na Perspectiva da Educação Inclusiva tem como objetivo endossar o acesso, a participação e a aprendizagem dos alunos público-alvo da Educação Especial na escola regular, orientando para que o aluno tenha o acompanhamento do Atendimento Educacional Especializado (AEE), não sendo substitutivo ao ensino regular, mas uma transversalidade da Educação Especial e, ainda, tem o objetivo de garantir a formação de professores, a participação da família e da comunidade, a acessibilidade e a articulação entre as partes envolvidas para colaborar na implementação das políticas públicas (BRASIL, 2008).

O Atendimento Educacional Especializado tem como função complementar e/ou suplementar a formação dos alunos, além de "identificar, elaborar e organizar recursos pedagógicos e de acessibilidade que eliminem as barreiras para a plena participação dos alunos, considerando suas necessidades específicas” (BRASIL, 2008, p. 15).

Nesse sentido, a sala de recursos multifuncionais (SRM) trata-se de um espaço organizado com equipamentos de informática, materiais pedagógicos, mobiliários adaptados e ajudas técnicas, com o objetivo de atender às peculiaridades de cada pessoa público-alvo da Educação Especial. 
De acordo com a nota técnica SEESP/GAB/Nº 11/2010 (BRASIL, 2010), esse atendimento constitui oferta obrigatória pelos sistemas de ensino para apoiar o desenvolvimento dos alunos público-alvo da Educação Especial, em todas as etapas, níveis e modalidades, ao longo de todo o processo de escolarização. $\mathrm{O}$ acesso ao AEE constitui direito do aluno público-alvo, cabendo à escola orientar a família e o aluno quanto à importância da participação nesse atendimento.

Ao implantar a sala de recursos multifuncionais para oferta do AEE, compete à escola construir o Projeto Político Pedagógico, considerando as necessidades individuais de cada aluno, segundo Plano de AEE. Prevê, ainda, abranger no Projeto Político Pedagógico professor para o AEE, equipamentos, recursos e condições de acessibilidade para todas as deficiências. Deverá ser realizada a matrícula no AEE dos alunos público-alvo da Educação Especial que estejam matriculados em classes comuns na própria escola ou em outra escola de ensino regular, conforme a disponibilidade de vagas na escola (BRASIL, 2009).

Além disso, é preciso registrar no Censo Escolar a matrícula dos alunos público-alvo da Educação Especial tanto na sala comum quanto na sala de recurso multifuncionais. Sendo assim, é necessário que haja uma articulação pedagógica entre professores da sala comum e da sala de recursos, a fim de viabilizar a participação e aprendizagem dos alunos, estabelecendo apoio mútuo entre eles. Essa rede de colaboração poderá ser estabelecida não só entre os professores, mas com as demais redes de ensino e centros de AEE, para, juntos, promoverem a inclusão dos alunos público-alvo da Educação Especial, devendo, portanto, produzir materiais didáticos, recursos de acessibilidade e estratégias pedagógicas (BRASIL, 2008).

Os sistemas de ensino, com base na Resolução CNE/CEB 02/2001, estabelecem normas para as escolas, a fim de que tenham condições suficientes para educação especial na educação básica. Com isso, faz-se necessário professores capacitados, ou seja, aptos para abranger todos os tipos de deficiência e atuar nas classes comuns em parceria com professores que possuam especialização em Educação Especial, para atender todas as demandas dos alunos público-alvo da Educação Especial (BRASIL, 2001). Desta forma, estabelece a Lei de Diretrizes e Bases da Educação Nacional, em seu art. 59:

III - professores com especialização adequada em nível médio ou superior, para atendimento especializado, bem como professores do ensino regular capacitados para a integração desses educandos nas classes comuns (BRASIL, 1996, p. 25).

Neste sentido, para que os professores sejam considerados especializados em Educação Especial, é importante ter formação superior em curso de graduação em Educação Especial, ou em Educação (Pedagogia), mas com conteúdo consistente em sua grade curricular da área de Educação Especial ou, ainda, pós-graduação em áreas específicas da Educação Especial. Já aos professores que possuem o magistério deve ser oferecida formação continuada pelas instâncias educacionais da União, dos Estados, do Distrito Federal e dos Municípios. Dessa forma, de acordo com a resolução citada, consideram-se professores especializados em Educação Especial:

[...] aqueles que desenvolveram competências para identificar as necessidades educacionais especiais para definir, implementar, liderar e apoiar a implementação de estratégias de flexibilização, adaptação curricular, procedimentos didáticos pedagógicos e práticas alternativas, adequadas aos atendimentos das mesmas, bem como trabalhar em equipe, assistindo o professor de classe comum nas práticas que são necessárias para promover a inclusão dos alunos com necessidades educacionais especiais (BRASIL, 2001, p. 5).

Neste âmbito, as Diretrizes Nacionais para a Educação Especial na Educação Básica estendem-se para todos os níveis e modalidades da Educação Básica. Tais proposições possuem o objetivo de impactar a formação inicial dos professores, tendo em vista a pouca formação para a área da Educação Especial ofertada nos currículos dos cursos de formação. Em vista disso, para viabilizar uma aprendizagem significativa dos alunos, é fundamental que haja uma articulação entre o professor do ensino regular e o da educação especial, juntamente com a gestão da escola, para que, juntos, planejem as ações que serão aplicadas em sala de aula para o desenvolvimento social e escolar dos alunos com deficiência, com transtornos globais do desenvolvimento e com altas habilidades ou superdotação. 
A Educação Inclusiva envolve um projeto de escola, baseada em um princípio filosófico, que se avança à igualdade de oportunidades, ao direito à diversidade e que atende todos os seus alunos em suas especificidades. No entanto, é um processo marcado por desafios e contradições que os sistemas educacionais ainda enfrentam. São desafios relacionados: à formação de professores e outros profissionais da escola; à definição de papéis e responsabilidades de professores e cuidadores; às práticas pedagógicas inclusivas; à relação família-escola; à aceitação da diversidade; à estrutura física das escolas; à aquisição de materiais pedagógicos e de acessibilidade; à cultura do trabalho colaborativo (MATOS; MENDES, 2014).

Marin e Zeppone (2012) argumentaram, em sua pesquisa, que a inclusão dos alunos com deficiência nas salas de aula comuns gera impactos no trabalho docente e também impactos pessoais em cada professor, como insegurança e medo, porém, ao mesmo tempo, mobiliza os professores a encontrarem forças para enfrentar os conflitos.

Nessa perspectiva, o ensino colaborativo é um modelo de ensino, cuja parceria entre os professores vem se tornando uma estratégia extremamente importante para o planejamento, práticas pedagógicas, avaliação e organização de recursos para o processo de inclusão. O ensino colaborativo visa a parceria entre professor do ensino regular, professor do AEE e os demais profissionais que compõem a escola.

O professor do AEE pode colaborar com o trabalho do professor da sala comum, uma vez que sua função abrange $o$ atendimento dos alunos público-alvo da educação especial que estão inseridos na sala regular. Cabe também ao professor do AEE orientar professores e famílias sobre os recursos pedagógicos e de acessibilidade utilizados pelo aluno e, ainda, desempenhar o trabalho de articulador e colaborador com os setores internos, mas também com os setores externos à escola que possam apoiar o desenvolvimento do aluno (BRASIL, 2009).

Considerando que o professor do AEE executa diversas tarefas, concorda-se com Vaz (2013, p. 183) que, "ao refletir as atribuições do professor, compreende a "multifuncionalidade” de suas ações e sugere a conceituação de professor multifuncional”.

Portanto, o professor do AEE necessita de uma formação que contemple as diversas atividades. A formação envolve conhecimentos que são próprios do AEE, estabelecendo uma relação com a realidade escolar do aluno, mas também deve contemplar as especificidades da Educação Especial, de modo que o professor possa desenvolver uma ação pedagógica, contemplando as necessidades dos alunos (ROSSETO, 2015).

Considera-se que, assim como o professor da sala comum, o professor do AEE pode ter uma sobrecarga de trabalho, mas também pode ter a atribuição da responsabilidade de transformar o sistema de ensino inclusivo (VAZ, 2013). Entretanto, também considera-se que efetivar a inclusão é responsabilidade de toda a comunidade escolar e, de modo mais geral, de toda a sociedade.

Nessa conjuntura, de acordo com a autora Damiani (2004) e com outros pesquisadores na área da cultura colaborativa, as escolas que investem nesse tipo de cultura têm enormes benefícios, dentre eles a diminuição da evasão, menor índice de repetência e alto grau de satisfação por parte dos professores pelo investimento na formação continuada dos docentes. Além disso, a formação continuada é um espaço de aprendizagem que permite identificar, por meio da socialização dos conhecimentos, as dúvidas e os anseios dos professores.

Na colaboração, os membros de um grupo, ao trabalharem juntos, se ajudam mutuamente, visando atingir objetivos comuns que foram negociados no coletivo, sendo assim, estabelecem relações não-hierarquizadas, mas estabelecem uma parceria dividindo a corresponsabilidade das ações desenvolvidas no ambiente escolar e fora dele (DAMIANI, 2008, p. 215).

Trabalho colaborativo nada mais é do que a divisão de responsabilidades como de planejar, instruir e avaliar a instrução de um grupo heterogêneo de estudantes. E o coensino é uma estratégia de inclusão escolar que busca favorecer a participação e a aprendizagem da criança na classe comum, e foi desenvolvido para evitar sistemas de retiradas ou de escolarização separados de alunos público-alvo da educação especial em sala de recursos multifuncionais (MENDES; VILARONGA; ZERBATO, 2014, p. 108).

Observa-se que ainda há dificuldades, por parte de alguns professores do ensino regular, em lidar com esse tipo de trabalho, uma vez que ainda prevalece uma certa inclinação em atribuir tarefas ao 
professor do AEE e se dedicar apenas ao restante do grupo de estudantes, ou então, o professor do AEE considera que ele é o responsável pelos alunos público-alvo da Educação Especial e não compartilha seu conhecimento e trabalho com o professor do ensino regular. Quando isso acontece, é necessário que haja um esclarecimento inicial de ambos professores, para que se tenha um trabalho colaborativo eficaz na escola.

Ao trabalharem em conjunto de forma colaborativa, os membros de um grupo se apoiam, estabelecendo relações na qual ambos buscam um único objetivo; isso pode ser entendido como uma estratégia pedagógica, a fim de favorecer o aprendizado do estudante de maneira mais significativa.

Um estudo que teve como foco o estabelecimento de ações colaborativas foi realizado pela professora doutora Barbara Carvalho Ferreira e colaboradores (2007) da Universidade Federal de São Carlos, em uma escola do município de São Paulo. Participaram do estudo 37 crianças da mesma faixa etária e, dentre elas, uma criança que tinha deficiência visual (cego congênito) e que foi o participante principal do estudo. O estudante era alfabetizado pelo sistema Braille, fazia aulas de informática, natação e treino com bengala.

No primeiro momento, a pesquisadora teve uma conversa inicial com a diretora e algumas professoras do aluno para explicar como se daria o trabalho e do que se tratava o ensino colaborativo. Dentre as cinco professoras que tinham contato com o aluno, apenas uma, a professora de português, entendeu a proposta do trabalho colaborativo, e voluntariamente se envolveu no caso. O trabalho foi planejado, discutido e elaborado com a direção, que teve o papel imprescindível no manejo do ambiente, e com a professora de português, que foi a única a demonstrar interesse e disponibilidade para participar (FERREIRA et al., 2007).

Nesse trabalho, a parceria colaborativa ocorreu na sala de aula entre a professora de português e a professora da Educação Especial, onde foi ministrado um curso, que teve duração de três meses, uma vez na semana. O processo colaborativo resultou, portanto, em aperfeiçoamento de estratégias que já eram utilizadas pela professora da sala comum e ajudou na criação de alguns manejos para tornar o ambiente mais adequado para aquele aluno (FERREIRA et al., 2007).

Roldão (2007, p. 28) defendeu que trabalhar colaborativamente implica "que cada indivíduo tenha um contributo a dar, que tem de ter o seu processo de construção individual e singular, que requer também tempos e modos de trabalhar individuais”. Neste sentido, a autora considera importantes esses momentos individuais para que o professor possa aprofundar seus conhecimentos de maneira que ele tenha algo a contribuir com o grupo. E em grupo, em um ambiente mais colaborativo, os professores podem se aperfeiçoar:

Quando os professores receiam partilhar as suas ideias e sucessos, com medo de serem considerados exibicionistas; quando mostram relutância em contar aos outros uma nova ideia, com medo que estes possam roubar e retirar daí vantagens pessoais; quando eles, novos ou velhos, receiam pedir ajuda porque poderiam ser considerados menos competentes, quando um educador utiliza a mesma abordagem, ano após ano, embora ele não esteja a resultar todas estas tendências reforçam os muros do privatismo. Tais processos limitam o crescimento e o aperfeiçoamento de forma decisiva, pois restringem o acesso às ideias e práticas que poderiam sugerir formas mais adequadas de proceder (FULLAN; HARGREAVES, 2001, p. 75).

A inclusão escolar demanda a construção de uma cultura colaborativa nas escolas, de modo que reuniões semanais aconteçam entre a gestão escolar, professores e familiares (e, se possível, outros setores da sociedade) para estudar o caso de algum aluno específico e buscar soluções e práticas que favoreçam o desenvolvimento do aluno (MATOS; MENDES, 2014). 


\section{OBJETIVO}

A partir desse contexto apresentado, o objetivo do estudo é analisar a percepção de professores acerca da inclusão e do Atendimento Educacional Especializado nas escolas municipais do Estado da Paraíba ${ }^{1}$.

\section{MATERIAL E MÉTODO}

\section{ASPECTOS ÉTICOS EM PESQUISA}

Anteriormente ao início das atividades da pesquisa, cumprindo as recomendações da Resolução 466/12 e da Norma Operacional nº 001/13 do Conselho Nacional de Saúde, que versa sobre Ética em Pesquisa com seres humanos, o projeto de pesquisa foi submetido à avaliação pelo Comitê de Ética, por meio da Plataforma Brasil, e foi aprovado, sob número 92373018.0.0000.5188. Cabe ressaltar que este trabalho é resultado de uma parte do projeto de pesquisa. Além disso, anteriormente ao início das atividades, as professoras assinaram o Termo de Consentimento Livre e Informado e concordaram com a realização do estudo.

\section{PARTICIPANTESE LOCAIS DA PESQUISA}

Participaram do estudo quatro professoras do Estado da Paraíba, sendo duas de uma escola do município de João Pessoa de Educação Infantil e Ensino Fundamental I e duas de uma escola do município de Cabedelo também de Educação Infantil e Ensino Fundamental I. Em cada uma das escolas, foram entrevistadas duas professoras: uma da sala comum e outra do Atendimento Educacional Especializado. Por motivos éticos, foram omitidos os nomes das escolas, passando-se a chamar por escola "A" a escola de João Pessoa e por escola "B” a escola de Cabedelo, e o nomes das professoras também foram mantidos em sigilo.

As professoras foram nomeadas da seguinte forma: a professora da sala comum de João Pessoa de "P1", a professora do AEE de João Pessoa de "P2", a professora da sala comum de Cabedelo de "P3" e a professora do AEE de Cabedelo de "P4".

\section{PROCEDIMENTOS DE COLETA E ANÁLISE DE DADOS}

O presente estudo trata-se de uma pesquisa qualitativa e descritiva. Para a coleta de dados, foi elaborado um roteiro de entrevista semiestruturado. Para Manzini (1991, p. 154), “a entrevista semiestruturada está focalizada em um assunto sobre o qual confeccionamos um roteiro com perguntas principais, complementadas por outras questões inerentes às circunstâncias momentâneas à entrevista”.

Os dados foram coletados em situações e ambientes diferentes. Primeiramente, foi-se à escola B e foi realizada a entrevista com a professora "P3", no momento em que ela estava em seu horário vago. A entrevista foi realizada na sala da coordenação da escola. Em um segundo momento, foi-se à escola novamente entrevistar a professora "P4" e a entrevista foi realizada na SRM. Em outro momento, foi-se à escola "A", na qual a primeira entrevista foi com a professora "P1", durante seu momento de intervalo, na sala dos professores, em seguida, foi entrevistada a professora "P2" na SRM.

As entrevistas foram gravadas em áudio, por meio de um celular. Após as entrevistas, elas foram transcritas e foram estabelecidos temas de análise de conteúdo. Foram utilizados temas de análise, pois um mesmo assunto descrito em um tema pode ser discutido também em outro tema estabelecido. $\mathrm{O}$ instrumento utilizado neste trabalho para a coleta dos dados foi escolhido pelo fato de as professoras

${ }^{1}$ Esta pesquisa é parte do Trabalho de Conclusão de Curso em Pedagogia da primeira autora. 
poderem descrever com mais clareza a sua função e as relações com as professoras do Atendimento Educacional Especializado.

\section{RESULTADOS E DISCUSSÃO}

A partir da leitura dos dados, foram estabelecidos temas de análise de conteúdo que estão representados no Quadro 1, a seguir e, com o objetivo de melhor visualização, junto com sua apresentação descritiva.

QUADRO 1 - TEMAS DE ANÁLISE

\begin{tabular}{|c|c|}
\hline TEMAS DE ANÁLISE & DESCRIÇÃO \\
\hline Formação & Refere-se à formação acadêmica das professoras. \\
\hline Inclusão & $\begin{array}{l}\text { Refere-se à concepção das professoras a respeito da inclusão de } \\
\text { alunos público-alvo da Educação Especial. }\end{array}$ \\
\hline $\begin{array}{l}\text { Recursos e estratégias pedagógicas e de } \\
\text { acessibilidade }\end{array}$ & Refere-se aos recursos e estratégias utilizadas pelas professoras. \\
\hline Atendimento Educacional Especializado & $\begin{array}{l}\text { Refere-se ao atendimento destinado ao público-alvo da Educação } \\
\text { Especial no ensino regular. }\end{array}$ \\
\hline Trabalho colaborativo & Ação conjunta que visa um objetivo comum. \\
\hline
\end{tabular}

FONTE: OS AUTORES

Com base nos dados, analisando as relações entre os estudos teóricos aliados às percepções das professoras, ponderaram-se os seguintes temas de análise que podem favorecer a visão acerca da inclusão de alunos público-alvo da educação especial e do Atendimento Educacional Especializado.

\section{FORMAÇÃO}

Analisando as entrevistas nas escolas "A" e "B", considerando as falas das professoras sobre formação, evidenciou-se que P1 e P2 possuem a graduação em Pedagogia e especialização em Psicopedagogia. Além disso, P2 tem especialização em Educação Inclusiva. A professora P3 possui formação em Pedagogia e Letras e P4 é pedagoga, especialista em AEE, Psicopedagogia Clínica e Institucional e mestre em Educação, na linha de Políticas Educacionais.

Considerando-se a formação das professoras, é importante ressaltar que o processo se dá de forma contínua, o que vem ao encontro do que reforça Bueno (2008), de que a educação inclusiva exige que não só o professor do ensino regular seja preparado em seu processo de formação para atender os alunos com deficiência, como os professores especialistas precisam ampliar suas ações, as quais geralmente são centradas nas características peculiares dos alunos relativas à deficiência.

Neste sentido, ao perguntar às professoras: você tem alguma formação em Educação Especial? Se sim, qual? Todas, exceto P3, responderam que: "sim, em Psicopedagogia”.

Nesta conjuntura, percebe-se que as professoras associam a especialização em Psicopedagogia como uma formação que as habilita para atuar com a diversidade de pessoas público-alvo da educação especial.

Ponderando ainda acerca da formação das professoras entrevistadas, pode-se destacar que a especialização em Psicopedagogia, por si só, não fornece subsídios suficientes para que os professores atendam a diversidade de pessoas público-alvo da educação especial, pois o foco do seu estudo é a formação de profissionais habilitados para o diagnóstico e a intervenção em distúrbios e déficits do processo de ensino-aprendizagem.

De acordo com as Diretrizes Nacionais para a Educação Especial na Educação Básica, o professor do AEE precisa ter formação inicial que o habilite para o exercício da docência e formação específica em Educação Especial. A Educação Especial se volta completamente à tarefa de complementar 
a formação, de modo que engloba todos os tipos de deficiência, sejam elas: física, auditiva, visual, intelectual, surdocegueira, múltipla, transtorno do espectro autista e, ainda, altas habilidades ou superdotação (BRASIL, 2001).

A título de exemplo, cita-se o curso privado de especialização em Psicopedagogia do Centro Universitário de João Pessoa - Unipê, que contempla, na sua estrutura curricular, apenas uma disciplina específica que envolve a Educação Especial - "Psicopedagogia e Inclusão: síndromes, deficiências sensoriais, cognitivas, motoras e múltiplas” (UNIPÊ, 2018).

Vale ressaltar também que o curso de Pedagogia da Universidade Federal da Paraíba, em sua estrutura curricular, possui apenas as disciplinas obrigatórias de Libras e de Educação Especial. Mas, como formação complementar obrigatória, no final do curso, o aluno pode escolher fazer um semestre de Aprofundamento em Educação Especial ou Aprofundamento em Educação de Jovens e Adultos (UNIVERSIDADE FEDERAL DA PARAÍBA, 2006).

Contudo, evidencia-se que as professoras do AEE, P2 e P4 têm formação adequada de acordo com a legislação, pois possuem especialização em Educação Inclusiva e em Atendimento Educacional Especializado, respectivamente. Entretanto, os desafios da formação continuam, porque as instituições de ensino ainda falham em empreender ações efetivas que favoreçam a formação de seus professores para trabalhar com a inclusão. Deste modo, os cursos oferecidos pelos poderes públicos têm sido insuficientes (MATOS; MENDES, 2014).

\section{INCLUSÃO}

Sobre a realidade da inclusão de crianças público-alvo da educação especial no ensino regular, as professoras da sala comum responderam:

P1: Eu tenho observado que o professor da sala regular, a grande maioria, não está preparado para receber os alunos com deficiência.

P3: É muito importante, muito interessante, porém deixa muito a desejar porque não tem materiais adequados disponíveis que são necessários para eles. E também, algumas vezes, os cuidadores dificultam um pouco a aprendizagem por questão de relacionamento [...] falta estrutura por parte da escola até para os alunos ditos normais [...]

O cuidador, como P3 mencionou, é denominado como profissional de apoio escolar, que tem como função exercer atividades de alimentação, higiene e locomoção do aluno com deficiência e atua em todas as atividades escolares necessárias, em instituições públicas e privadas (BRASIL, 2015).

Matos e Mendes (2014) afirmaram que uma das demandas decorrentes para a inclusão escolar é a definição de papéis e responsabilidade de professores e cuidadores. As autoras evidenciaram que raramente professores e cuidadores dialogam na escola, mesmo quando há divergências no modo de intervir com a criança público-alvo da educação especial. Assim, há necessidade de uma formação que contemple o desenvolvimento de habilidades interpessoais para que o professor possa trabalhar colaborativamente também com o cuidador, além do professor do AEE e outros atores da escola.

Já para as professoras do AEE foi questionado como o AEE pode contribuir para que o planejamento pedagógico seja inclusivo. As professoras responderam:

P2: Dando estratégias e meios aos professores de não trabalhar só em cima do livro da leitura e da escrita, mas tentando inserir aos poucos, porque tem muito professor que é resistente, o lúdico, principalmente quando é para eles confeccionarem [...]

P4: Elaborando estratégias em colaboração com o professor da sala de aula regular, bem como aquele que produz e executa na sala de recurso sejam partilhadas com os demais profissionais envolvidos, em especial o professor que atua com a criança, vendo seus efeitos para se pensar num replanejamento[...] 
Para que a inclusão se consolide, reconhece-se ser necessária uma mobilização em vários âmbitos, como o social, econômico e político. No entanto, o empenho do professor interfere de forma decisiva para o sucesso ou não da inclusão dos alunos público-alvo da Educação Especial na escola. Nessa perspectiva, concorda-se com Minetto:

Quanto mais conhecemos determinado fato ou assunto, mais nos sentimos seguros diante dele. O novo gera insegurança e instabilidade, exigindo reorganização, mudança. É comum sermos resistentes ao que nos desestabiliza. Sem dúvida, as ideias inclusivas causaram muita desestabilidade e resistência (MINETTO, 2008, p. 17).

Neste sentido, compete aos professores buscar novas posturas e habilidades que permitam problematizar, intervir nas diferentes situações, a fim de que haja mudanças significativas para a construção de uma proposta voltada para inclusão.

Todavia, esse trabalho não se restringe apenas aos professores. Para que haja, de fato, a inclusão, não basta apenas inserir os alunos nas atividades na sala de aula, socializar com os colegas, mas é necessário o envolvimento dos gestores, das políticas públicas, de todos, sem exceção. A professora P4 diz que:

P4: Esse é um ponto que deve ser trabalhado em conjunto com todos os sujeitos envolvidos, a começar pela coordenação pedagógica, ela tem papel decisivo porque o coordenador pedagógico é o profissional responsável por todo esse acompanhamento, os professores também, com relação à sala de recursos, deve ser mediada de acordo com a necessidade da criança, o professor da sala regular pode sinalizar essas dificuldades e vice-versa, e o professor da sala de recurso na produção do seu plano de atendimento para atender essa criança e sugerindo também atividades diferenciadas [...]

Sendo assim, o AEE visa a complementação ou suplementação do ensino, e fica claro que o professor precisa trabalhar em parceria com o da sala comum, de modo que promova a inclusão dos alunos. Para isso, é necessário que o professor tenha conhecimentos específicos em Educação Especial para poder articular de maneira coerente os atendimentos.

\section{RECURSOS E ESTRATÉGIAS PEDAGÓGICAS E DE ACESSIBILIDADE}

Ao abordar o tema recursos de acessibilidade, nas entrevistas, foi observado que, por meio de suas falas, as professoras somente disseram sobre recursos para a acessibilidade arquitetônica e apenas uma professora, P1, abordou sobre a acessibilidade para uso do material escolar. Foi questionado se os alunos precisavam de algum recurso, quais os recursos que eles precisavam e quem acompanhava o uso desses recursos. As professoras responderam contradizendo acerca de quem seria a responsabilidade do acompanhamento do uso dos recursos:

P3: A escola precisa de espaço para diversão, salas amplas e materiais adequados e quem acompanha o uso dos recursos é o cuidador.

P4: Alguns cadeirantes precisam de apoio e quem acompanha o uso desses recursos é toda equipe escolar.

P1: Sim [...] rampas, que já têm na escola, porque ele anda com dificuldade, e o banheiro já é adaptado [...] eles precisam de adaptação no lápis e nos objetos porque ele tem dificuldade para manipular coisas devido à paralisia cerebral, e quem acompanha o uso desses recursos é a cuidadora.

A respeito da existência de rampas, percebe-se a contradição na fala de P2:

P2: O que precisamos hoje é de umas rampas para todas as salas de aula, todos os cômodos da escola que tenha batente e que não tem, inclusive a sala de AEE tem um batente [...] a escola precisa de rampas e passarelas, e quem acompanha o uso desses recursos é a direção e a professora do AEE. 
Diante disso, foi possível constatar que houve divergência de respostas entre as professoras. Conforme as Diretrizes Operacionais para o Atendimento Educacional Especializado na Educação Básica, modalidade Educação Especial, o professor do AEE tem a função de acompanhar a funcionalidade e aplicabilidade dos recursos pedagógicos e de acessibilidade na sala de aula comum e nos demais espaços escolares (BRASIL, 2009).

Conforme previsto pela Política Nacional de Educação Especial na Perspectiva da Educação Inclusiva, o AEE "tem como função identificar, elaborar e organizar recursos pedagógicos e de acessibilidade que eliminem as barreiras para a plena participação dos alunos público-alvo da Educação Especial (BRASIL, 2008).

Vale salientar, ainda, que mediante observação do espaço escolar, no momento da entrevista, verificou-se que as escolas dispunham de recursos pedagógicos e de acessibilidade para que fosse realizado o Atendimento Educacional Especializado, no entanto, esses materiais podem não estar acompanhando o aluno para as professoras do ensino regular também utilizarem. Conforme a professora do ensino regular P3 afirmou:

\section{P3: Falta material, falta espaços, falta estrutura física.}

Diante disso, em concordância com os autores Lauand e Mendes (2008), muitas vezes, as pessoas que trabalham com o público-alvo da educação especial desconhecem ou subutilizam os recursos e equipamentos de tecnologia assistiva, bem como outros recursos, o que pode ter um impacto significativo na inclusão seja social ou escolar. Entretanto, cabe ressaltar que, mesmo a escola possuindo determinados recursos, é possível afirmar que as escolas não estão suprindo as demandas necessárias para a realização de um trabalho pedagógico, de fato, com qualidade e inclusivo (MATOS; MENDES, 2014).

Acerca de possíveis adaptações pedagógicas para os alunos público-alvo da educação especial, as professoras do AEE se omitem da realização dessas atividades e lançam a responsabilidade em cima das professoras do ensino regular, como pode-se observar, a seguir:

P1: Eu acredito que deveria, além de eu mesma fazer, vir da Prefeitura alguns materiais que favorecessem a aplicação de atividades.

P2: O professor da sala regular, porque o aluno não é aluno do AEE, ele é aluno da escola. Então, quando ele vem se matricular, ele faz a matrícula na escola, então ele é um aluno como qualquer um outro; ele tem um laudo que comprova que tem uma limitação, aí sim ele tem a dupla matrícula que é no AEE, mas antes de ele chegar no AEE, seja com laudo ou não, passou primeiro para o ensino regular, e isso diz na LDB: que o aluno, independente da deficiência, tem a garantia da matrícula. Então no meu ponto de vista, de professor do AEE, quem deve adaptar essas atividades é o professor da sala regular.

P3: O professor (referindo-se ao professor do ensino regular).

Apenas a professora P4 respondeu conforme a regulamentação da função do professor do AEE:

P4: O professor da sala de recursos tem essa função, inclusive essa é uma função regulamentada garantida na especificidade da sua função e o professor da sala regular também tem essa responsabilidade no tocante ao seu planejamento.

Nesta conjuntura, foi possível perceber o equívoco na fala da P2, pois sendo a mesma professora do AEE, acredita não ter a responsabilidade de fazer as adaptações curriculares e joga a responsabilidade para o professor do ensino regular. Segundo ela, o aluno, antes de ser matriculado no AEE, já vem do ensino regular.

A respeito das adaptações pedagógicas, a Lei Brasileira de Inclusão da Pessoa com Deficiência assegura que:

Art. 28. Incumbe ao poder público assegurar, criar, desenvolver, implementar, incentivar, acompanhar e avaliar: [...] 
III projeto pedagógico que institucionalize o atendimento educacional especializado, assim como os demais serviços e adaptações razoáveis, para atender às características dos estudantes com deficiência e garantir o seu pleno acesso ao currículo em condições de igualdade, promovendo a conquista e o exercício de sua autonomia [...] (BRASIL, 2015, p. 7).

Desta forma, neste trabalho, há a compreensão de que as adaptações pedagógicas não são o estabelecimento de um outro currículo para os alunos público-alvo da educação especial, mas sim a garantia de condições de acesso, permanência, participação e aprendizagem, eliminando as barreiras que impedem a inclusão plena desses alunos no ensino regular (BRASIL, 2015).

Nessa perspectiva, o AEE é responsável por eliminar as barreiras para que o aluno público-alvo da educação especial possa frequentar o ensino regular em condições de igualdade com os demais alunos. Diante disso, o objetivo maior do professor do AEE é conhecer o aluno, identificar suas necessidades e possibilidades, delinear um plano de AEE, para que possa organizar os recursos pedagógicos e de acessibilidade e traçar estratégias.

\section{ATENDIMENTO EDUCACIONAL ESPECIALIZADO}

O AEE é definido como um conjunto de atividades, recursos de acessibilidade e pedagógicos para complementar e/ou suplementar o ensino regular, portanto, não tem caráter substitutivo, e sim auxiliar (BRASIL, 2008; 2009).

Para saber mais sobre como as professoras entendiam o AEE e a sua função na escola, as professoras foram questionadas e responderam:

P2: Atendimento educacional especializado, para mim, dá meios e subsídios para que a criança desenvolva principalmente a parte da vida diária como a questão da aprendizagem. Nós, do AEE, damos subsídios para que ela desenvolva isso, a atividade da vida diária como também a aprendizagem e isso através de diversos meios tecnológicos lúdicos, a gente faz de tudo para que ele desenvolva.

P4: É uma modalidade pertencente à educação especial, onde as crianças devem ser atendidas preferencialmente no contraturno ela não é substitutiva, no caso ao ensino de sala regular ele funciona como um complemento no contraturno para crianças, de preferência.

Diante disso, cabe ressaltar que o AEE não pode substituir atividades curriculares próprias da Educação Infantil, do Ensino Fundamental, ou seja, do ensino comum, mas deve ajudar a minimizar as barreiras que impedem a plena participação dos alunos em todos os ambientes escolares. A partir das entrevistas com as professoras, foi evidenciado que nem sempre isso ocorre:

P1: Eu acredito que, para melhorar, o aluno deveria vir no horário oposto porque, como é uma vez por semana, de 30 a 40 minutos não é o suficiente.

P3: Funciona nos dois turnos, cada turno recebe os alunos do horário. Eles têm horário, têm atendimento com os pais e é muito bom esse atendimento.

P4: A sala de recursos é institucionalizado no início do ano, começamos primeiramente pelo levantamento das crianças que têm deficiência, fazemos as matrículas. Feitas as matrículas com os pais, nós planejamos o atendimento das crianças, então as crianças são atendidas de preferência no contraturno, algumas não conseguem ser atendidas, decorrente da dificuldade dos próprios pais, que não podem trazer, etc. nós atendemos em dupla, individual, depende, fazemos atendimentos dessa forma [...]

Nessa conjuntura, é importante também trazer a questão de que, quando o aluno sai da sala de aula e vai para a sala de recursos multifuncionais, que deveria ser no turno oposto, há uma quebra no raciocínio das crianças, elas perdem conteúdos acadêmicos e deixa de aprender coisas essenciais que talvez não irá aprender com o professor do AEE, pois naquele momento, muitas vezes, em experiências práticas vivenciadas, observa-se que a professora do AEE não procura saber o conteúdo que a professora 
do ensino comum está ministrando, ela simplesmente pega o aluno e leva-o para o atendimento na sala de recurso multifuncional.

Conforme a Resolução CNE/CEB 4/2009, o Atendimento Educacional Especializado é realizado, prioritariamente, na sala de recursos multifuncional, devendo ser realizado no turno inverso à escolarização, não sendo substitutivo ao ensino regular, mas uma transversalidade da educação especial, incluindo a formação de professores, a participação da família e da comunidade, a acessibilidade e a articulação entre as partes envolvidas para colaborar na implementação das políticas públicas (BRASIL, 2009).

Além disso, o Atendimento Educacional Especializado também pode ocorrer dentro da sala de aula comum, em um trabalho de coensino com o professor do ensino regular. Logo, o professor do AEE deve contribuir para que o planejamento pedagógico seja inclusivo, eliminar as barreiras para plena participação dos sujeitos, capacitar os professores por meio de formação e envolver a participação da família e da comunidade, além de todos os membros da escola, a fim de promover a acessibilidade e inclusão dos alunos público-alvo da Educação Especial.

Nesse processo, a gestão escolar tem um papel fundamental para proporcionar esses espaços de articulação e formação. Os processos de organização e gestão das escolas são fatores imprescindíveis para promover a qualidade e equidade da educação (CAPELLINI, 2004).

\section{TRABALHO COLABORATIVO}

O trabalho colaborativo é uma estratégia pedagógica essencial e indispensável para promover a aprendizagem dos alunos. Para o sucesso de ações inclusivas na escola, a favor de um objetivo comum, é necessário um trabalho em equipe que envolva todos os profissionais e, em especial, a parceria entre os professores do ensino regular e do AEE (CAPELLINI, 2004).

Assim, ao falar acerca do trabalho colaborativo entre as professoras da sala comum e do AEE, para saber como funcionava a interação entre elas, as professoras do AEE foram questionadas e responderam que dão apoio aos professores da sala comum, como mostram suas falas:

P2: Desde o primeiro contato, antes mesmo de o professor saber quem é a criança especial, eu já sei, então, muitas vezes, quem apresenta esse aluno para o professor sou eu, a partir daí, o nosso contato até a questão de planejamento, de conteúdo de avaliação de adaptação de atividade se for o caso. Então, a gente passa o ano todo trocando informações, inclusive muitas vezes tendo que chamar o pai, dependendo do comportamento ou do problema que a criança apresenta; chama o pai e eu, juntamente com a professora da sala regular, conversamos e fazemos a questão de interferência, vamos dizer assim, e fazer o que for preciso para o desenvolvimento da criança.

P4: Sim, nós temos inclusive um bom relacionamento com todos os professores, isso é fundamental para que a criança venha, de fato, ter a inclusão.

Entretanto, foi possível observar a contradição na fala de P1 quando diz que:

P1: [...] no começo do ano a gente faz o planejamento juntamente com a professora do AEE e discute algumas questões. E durante o decorrer do ano, quando possível, a gente se reúne. [...] a gente deveria trabalhar planejando mais, mais vezes por semana, estratégias para facilitar o entendimento do aluno.

Evidencia-se, no discurso de P2, uma contradição em relação à sua própria fala, quando foi discutido acerca das adaptações pedagógicas no tema "Recursos e estratégias pedagógicas e de acessibilidade". Naquele momento, P2 dizia que ela não era responsável pelas adaptações pedagógicas, pois antes de o aluno público-alvo da educação especial - com laudo ou sem laudo - chegar no AEE, ele chega primeiro no ensino regular. Já nesse momento, P2 diz que primeiramente é ela que sabe quem é o aluno e, muitas vezes, é ela que o apresenta para o professor do ensino regular.

Além disso, é perceptível, quando é analisada a fala de P1, que o encontro na escola entre ela e P2 acontece de forma esporádica durante o ano, que quando possível elas se reúnem para discutir questões 
relacionadas aos alunos público-alvo da educação especial. Nas falas de P1 e P2, é possível notar que elas parecem realizar um planejamento no início do ano, mas no decorrer do trabalho pedagógico durante o ano letivo, essa parceria se perde e a professora do ensino regular acabar desenvolvendo atividades e estratégias pedagógicas sozinha.

P2 se contradiz mais uma vez, quando é perguntado se existe o trabalho colaborativo entre o professor da sala comum e o do AEE:

P2: [...] na sexta-feira eu não atendo, na sexta-feira meu horário é livre para planejar tanto o meu planejamento mensal, como para atender a família e o professor. Os professores já sabem no horário de educação física deles, ensino religioso e arte, eles podem vir aqui tirar uma dúvida ou a gente conversar alguma coisa [...]

É possível observar pelo discurso de P2 que ela não faz um acompanhamento junto aos professores da e na sala comum, pois o dia em que ela está disponível, sem atender os alunos, é sexta-feira, entretanto, ela não vai atrás do professor para conversar com ele, de modo que o professor do ensino regular é que deve ir atrás dela, caso esteja precisando de alguma coisa ou com alguma dúvida. Ela deixa isso muito claro: os professores é que devem tirar suas dúvidas no horário livre dela. Dessa forma, fica inviável o contato direto com as professoras do ensino regular apenas nos horários em que elas estão disponíveis ou com horário vago e tem interesse em procurá-la.

Neste sentido, esses discursos notadamente demonstram que não existe o trabalho colaborativo na escola, conforme sugerem estudiosos da área (FERREIRA et al., 2007). Essa estratégia consiste na parceria entre professor do atendimento educacional especializado e o professor do ensino regular, na qual ambos dividem as responsabilidades de planejar, instruir e avaliar os procedimentos de ensino de um grupo.

Já a fala de P3 confirma as respostas de P4, demonstrando que pode haver uma determinada parceria ou trabalho colaborativo entre as professoras:

P3: a gente sempre senta, sempre discute, sempre chama os pais para conversar a cada necessidade. [...] ela sempre sugere jogos, ela sempre olha o caderno, para saber o que eu estou passando, a gente sempre troca informações, figurinhas.

No entanto, em outro momento, P3 desabafa a respeito da inclusão escolar e diz:

P3: não sabemos lidar com a situação às vezes[...] a gente fica só rebolando, usando jogo de cintura e a linguagem, o que a gente estudou e o que a gente viu na nossa prática e vai adaptando.

O processo de inclusão escolar é bastante desafiador, pois exige "recursos diferenciados e uma organização distinta do ensino” (ROSSETO, 2015, p. 112). Ademais, a inclusão impõe significativas modificações nas concepções, nas crenças, na redefinição de atuações e na criação de uma nova cultura escolar (CAPELLINI, 2004).

Ao perguntar se o Projeto Político Pedagógico (PPP) da escola possui ações que contemplam o trabalho colaborativo das professoras, apenas uma respondeu que sim, e que ela colaborava com as ações, como mostra a fala:

P4: Contém essas ações, inclusive tivemos oportunidade de participar e contribuir de forma documentada para depois facilitar sua execução.

As demais professoras não sabiam ou nunca leram o PPP da escola. Isso demonstra que o PPP da escola pode existir, mas por uma mera exigência legal.

Por fim, foi perguntado para as professoras sobre qual era a importância do trabalho colaborativo na escola. E elas responderam:

P1: É importante o envolvimento de todos na escola para que haja a inclusão de todos os alunos com necessidades especiais. 
P2: De grande importância, porque uma coisa que eu não consigo o professor pode conseguir ou até mesmo o cuidador, já que passam a tarde juntinhos e eles acabam dando mais respostas positivas para o cuidador do que para mim ou para o professor do AEE.

P3: É muito importante, porque como a gente vai avançar no processo de aprendizagem dessas crianças se não for compartilhando as informações?

P4: Fundamental para que a criança consiga alcançar seu desenvolvimento global dentro das suas especificidades, respeitando as características de cada criança, sem o trabalho colaborativo é difícil e fica até inviável que o professor do AEE venha a realizar um trabalho com êxito, uma vez que os maiores interessados são os professores, a criança e família nesse processo.

Como pode-se observar, todas responderam que o trabalho colaborativo é de suma importância e potencializa de maneira positiva a aprendizagem das pessoas com deficiência. Essa forma de trabalho requer que tanto os professores do AEE como os do ensino regular assumam a responsabilidade de atuarem juntos com o mesmo objetivo. Para Zabalza:

É através da troca e do apoio comum que as ligações necessárias surgem e os obstáculos podem ser ultrapassados; deste modo, julgamos poder afirmar que as dinâmicas colaborativas entre os docentes somente acontecem por desejo e escolha pessoal e não por imposição. Uma efetiva participação educativa passa pela modificação da atitude individualista do docente e pelo estabelecimento do respeito pelo trabalho dos parceiros pedagógicos (ZABALZA, 1998, p.16).

Deste modo, embora ainda haja dificuldades por parte de alguns professores, o trabalho colaborativo tem se mostrado uma alternativa eficaz para o desenvolvimento de uma aprendizagem mais significativa, para o desenvolvimento pessoal e profissional dos professores e para o sucesso da inclusão escolar (CAPELLINI, 2004; MENDES; VILARONGA; ZERBATO, 2014).

\section{CONSIDERAÇÕES FINAIS}

Este trabalho teve o objetivo de analisar a percepção de professores acerca da inclusão e do Atendimento Educacional Especializado nas escolas municipais do Estado da Paraíba. O estudo ampliou aspectos relevantes como discussões sobre a Educação Especial na perspectiva da Educação Inclusiva, o Atendimento Educacional Especializado e ações colaborativas. O método utilizado para coleta de dados foi fundamental para a pesquisa, pois proporcionou um olhar mais crítico sobre a percepção das professoras acerca do trabalho realizado nas escolas.

Diante dos dados analisados, evidencia-se a demanda por formação das professoras e pela gestão pessoal dos sistemas educacionais. A maioria das professoras não tem clareza de sua função na escola. Além disso, afirmaram que a Psicopedagogia é um curso que possibilita trabalhar com pessoas com deficiência, e não citam a área da Educação Especial como a responsável ao atendimento e à educação de pessoas com deficiência e altas habilidades ou superdotação. Os dados mostraram que cursos de formação docente inicial e continuada podem estar proporcionando apenas conhecimentos técnicos ou clínicos, que não possibilitam que os professores realizem, de fato, um trabalho educativo para o desenvolvimento integral do aluno.

Nesse âmbito, é preciso enfatizar que faz-se necessário professores capacitados, ou seja, aptos para ensinar todos os alunos, independente se tem alguma deficiência ou não e para atuar nas classes comuns em parceria com professores que possuam conhecimentos específicos em Educação Especial, ou seja, que colaborem com os processos de ensino-aprendizagem de alunos com os diversos tipos de deficiência e altas habilidades ou superdotação

O processo colaborativo é um desafio que pode ser superado, sobretudo, se os professores estabelecerem relações não-hierarquizadas, e não colocando as responsabilidades do aluno público-alvo da educação especial apenas sobre o professor do AEE ou sobre o professor do ensino regular. Ambos precisam assumir uma parceria, dividindo a corresponsabilidade das ações desenvolvidas no ambiente 
escolar. E ainda, toda a gestão, equipe escolar e a família devem estar envolvidas nesse processo para a construção de uma cultura inclusiva na escola e fora dela.

\section{REFERÊNCIAS}

BRASIL. Ministério da Educação. Lei no 9.394, de 20 de dezembro de 1996. Lei de Diretrizes e Bases da Educação Nacional. Diário Oficial da União. Disponível em: http://portal.mec.gov.br/seesp/arquivos/ pdf/lei9394_ldbn2.pdf. Acesso em: 4 maio 2019.

BRASIL. Conselho Nacional de Educação. Institui Diretrizes Nacionais para a Educação Especial na Educação Básica. Resolução n. 2, de 11 de setembro de 2001. Diário Oficial da União. Brasília, DF, p. 39-40, seção 1E, set. 2001.

BRASIL. Ministério da Educação. Secretaria de Educação Continuada, Alfabetização, Diversidade e Inclusão. Política de Educação Especial na Perspectiva da Educação Inclusiva. Brasília, DF, 2008.

BRASIL. Ministério da Educação. Conselho Nacional de Educação. Resolução nº 04 de 02 de outubro de 2009. Institui Diretrizes Operacionais para o Atendimento Educacional Especializado na Educação Básica, modalidade Educação Especial. Brasília, DF, 2009.

BRASIL. Ministério da Educação. Secretaria de Educação Especial Esplanada dos Ministérios. Nota Técnica - SEESP/GAB/No 11/2010. Orientações para a institucionalização da Oferta do Atendimento Educacional Especializado: AEE em Salas de Recursos Multifuncionais, implantadas nas escolas regulares. n. 11, Brasília, DF, 2010.

BRASIL. Lei no 13.146, de 06 de julho de 2015. Institui a Lei Brasileira de Inclusão da Pessoa com Deficiência (Estatuto da pessoa com deficiência). Diário Oficial da União, Brasília, DF, 7 de jul. 2015.

BUENO, J. G. S. As políticas de inclusão escolar, uma prerrogativa da educação especial. In: BUENO J.G.S; MENDES, G. M. L.; SANTOS, R. A. (org.). Deficiência e escolarização: novas perspectivas de análise. Araraquara: Junqueira \& Marin. Brasília: CAPES, 2008. p. 43-63.

CAPELLINI, V. L. M. F. A avaliação das possibilidades do trabalho colaborativo no processo de inclusão escolar do aluno com deficiência mental. 2004. 299 f. Tese (Doutorado em Educação Especial) - Universidade Federal de São Carlos, São Carlos, 2004.

DAMIANI, M. F. “Sem as reuniões a escola não existe! Não tem como!”: estudo de caso de uma escola colaborativa. In: REUNIÃO ANUAL DA ANPED, 27., 2004, Caxambu. [Anais] .... Caxambu, 2004. p. 1-15. CD-ROM.

DAMIANI, M. F. Entendendo o trabalho colaborativo em educação e revelando seus benefícios. Revista Educar, Paraná, n. 31, p. 213-230, jan. 2008. Disponível em: http://www.scielo.br/pdf/er/n31/n31a13. pdf. Acesso em: 20 jan. 2020.

FERREIRA, B. F. et al. Parceria Colaborativa: descrição de uma experiência entre o ensino regular e especial. Revista do Centro de Educação, São Paulo, n. 29, p. 1-7, out. 2007. Disponível em: https:// periodicos.ufsm.br/educacaoespecial/article/view/4137/2454. Acesso em: 23 jan. 2020.

FULLAN, M.; HARGREAVES, A. Por que é que vale a pena lutar? O trabalho de equipa na escola. Porto: Porto, 2001.

LAUAND, G. B. A.; MENDES, E. G. Aplicação das Tecnologias Assistivas, de Informação e Comunicação na Educação Especial. In: MENDES, E. G. (org.). Temas em Educação Especial: conhecimentos para fundamentar a prática. 1. ed. v. 1. Araraquara: Junqueira \& Marins Editores, 2008. p. 125-133.

MANZINI, E. J. A entrevista na pesquisa social. Didática, São Paulo, v. 26/27, p. 149-158, 1990/1991. 
MARIN, A. J.; ZEPPONE, R. M. O. O trabalho docente e a inclusão escolar: impactos e mudanças em sala de aula. Olhar de professor, Ponta Grossa, v. 15, n. 1, p. 145-155, 2012. Disponível em: https:// www.revistas2.uepg.br/index.php/olhardeprofessor/article/view/3625/3009. Acesso em: 20 abr. 2020.

MATOS; S. N.; MENDES, E. G. Demandas decorrentes da inclusão escolar. Revista Educação Especial, Santa Maria, v. 27, n. 48, p. 27-40, jan./abr. 2014. Disponível: https://periodicos.ufsm.br/ educacaoespecial/article/view/8796/pdf. Acesso em: 23 jan. 2020.

MENDES, E. G.; VILARONGA, C. A. R.; ZERBATO, A. P. Ensino colaborativo como apoio à inclusão escolar: unindo esforços entre educação comum e especial. São Carlos: UFSCar, 2014.

MINETTO, M. F. O currículo na educação inclusiva: entendendo esse desafio. 2. ed. Curitiba: IBPEX, 2008.

ONU - ORGANIZAÇÃO DAS NAÇÕES UNIDAS. Convenção sobre os Direitos das Pessoas com Deficiência, aprovada pela Assembleia Geral da ONU em dezembro de 2006. Disponível em: https://www. pessoacomdeficiencia.gov.br/app/sites/default/files/publicacoes/convencaopessoascomdeficiencia.pdf. Acesso em: 4 mai. 2019.

ROLDÃO, M. C. Colaborar é preciso: questões de qualidade e eficácia no trabalho dos professores. Noesis, n. 71, p. 24-29, out./dez. 2007.

ROSSETTO, E. Formação do professor do atendimento educacional especializado: a Educação Especial em questão. Revista Educação Especial, Santa Maria, v. 28, n. 51, p. 103-116, jan./abr. 2015. Disponível em: https://periodicos.ufsm.br/educacaoespecial/article/view/13367/pdf. Acesso em: 20 jan. 2020.

UNESCO. Declaração de Salamanca e Enquadramento da Acção na Área das Necessidades Educativas Especiais. Lisboa: Instituto de Inovação Educacional, 1994.

UNIPÊ. Centro Universitário. Psicopedagogia Institucional e Clínica. 2018. Disponível em: https:// unipe.br/pos-graduacao/psicopedagogia-institucional-e-clinica/. Acesso em: 20 set. 2018.

UNIVERSIDADE FEDERAL DA PARAÍBA. Centro de Educação. Estrutura Curricular Pedagogia. 2006. Disponível em: https://sigaa.ufpb.br/sigaa/link/public/curso/curriculo/1011. Acesso em: 20 set. 2018.

VAZ, K. O Professor de Educação Especial nas Políticas de Perspectiva Inclusiva no Brasil: concepções em disputa. 2013. 237 f. Dissertação (Mestrado em Educação) - Universidade Federal de Santa Catarina, Florianópolis, 2013. Disponível em: https://repositorio.ufsc.br/xmlui/bitstream/ handle/123456789/123143/322561.pdf?sequence=1\&isAllowed=y. Acesso em 20 abr. 2020.

ZABALZA, M. Qualidade em educação infantil. Porto Alegre: Artmed, 1998. 